\title{
CONCEPÇÕES DE ESTUDANTES DO ENSINO MÉDIO SOBRE A RELEVÂNCIA DO COMPONENTE CURRICULAR DE QUÍMICA
}

\author{
CONCEPTIONS OF MIDDLE SCHOOL STUDENTS ON THE
}

RELEVANCE OF THE CHEMISTRY DISCIPLINE

Mônica da Silva Gallon', Carla Melo Silva², Lorita Aparecida Veloso Galle 3 , Zulma Elisabete de Freitas Madruga ${ }^{4}$

\author{
Recebido em: 24 de abril de 2017 \\ Aprovado em: 25 de setembro de 2017 \\ Sistema de Avaliação: Double Blind Review \\ RCO | a. 10 | v. 1 | p. 3-13 | jan./jun. 2018 \\ DOI: https://doi.org/10.25112/rco.vli0.1178
}

\section{RESUMO}

O presente estudo aborda as concepções iniciais de estudantes do $1^{\circ}$ ano do Ensino Médio sobre a relevância do componente curricular de Química. Assim, o problema central da pesquisa é: Quais as concepções iniciais de estudantes do $1^{\circ}$ ano do Ensino Médio sobre a relevância do componente curricular de Química?. A investigação foi realizada com estudantes de três turmas do $1^{\circ}$ ano do Ensino Médio, totalizando 69 participantes, com idade média de 16 anos, pertencentes a uma escola pública estadual da região do Vale do Sinos, RS, Brasil. Para coleta de dados, o professor perguntou aos estudantes: Qual a relevância que você percebe na Química? Cabe ressaltar que o questionamento foi realizado por escrito na primeira semana de aula do ano letivo de 2016, antes do professor do referido componente iniciar o trabalho relacionado aos conteúdos para aquele ano. O material coletado foi analisado por meio de Análise Textual Discursiva (MORAES; GALIAZZI, 2013). A análise possibilitou compreender que os estudantes apresentam concepções distintas sobre a relevância do componente curricular de Química. Acredita-se que tais concepções tenham sido construídas por meio de vivências escolares, durante os anos anteriores de escolarização, e fortalecidas no $9^{\circ}$ ano do Ensino Fundamental, onde o componente de Ciências aborda tópicos relativos à Química, ou ainda, a partir do cotidiano desses estudantes. Os resultados obtidos podem auxiliar os professores deste componente curricular no sentido de desenvolverem práticas mais efetivas que proporcionem aos estudantes compreender a real função e relevância do estudo da Química, enquanto ciência.

Palavras-chave: Educação Básica. Ensino de Ciências. Ensino de Química. Concepções dos Estudantes. Química.

\footnotetext{
ABSTRACT

The present study approaches the initial conceptions of students of the 1st year of High School on the relevance of the curricular component of Chemistry. Thus, the central problem of the research is: What are the initial conceptions of students of the 1st year of High School on the relevance of the curricular component of Chemistry? The research was carried out with students from three classes of the 1st year of High School, totaling 69 participants, with a mean age of 16 years, belonging to a state public school

${ }^{1}$ Doutoranda em Educação em Ciências e Matemática pela Pontifícia Universidade Católica do Rio Grande do Sul (Porto Alegre/Brasil). E-mail: monica.gallon@gmail.com.

${ }^{2}$ Doutoranda em Educação em Ciências e Matemática pela Pontifícia Universidade Católica do Rio Grande do Sul (Porto Alegre/Brasil). E-mail: carlamelodasilva2015@gmail.com.

${ }^{3}$ Doutoranda em Educação em Ciências e Matemática pela Pontifícia Universidade Católica do Rio Grande do Sul (Porto Alegre/Brasil). E-mail: lorita.galle@acad.pucrs.br.

${ }^{4}$ Doutora em Educação em Ciências e Matemática pela Pontifícia Universidade Católica do Rio Grande do Sul (Porto Alegre/Brasil). Professora na Universidade Estadual de Santa Cruz (Ilhéus/Brasil). E-mail: betefreitas.m@bol.com.br.
} 
in the region of Vale do Sinos, RS, Brazil. For data collection, the teacher asked the students: How relevant do you perceive in chemistry? It should be noted that the questioning was done in writing in the first week of class in the 2016 school year, before the professor of chemistry began to work with the planned the course for that year. The collected material was analyzed through Discursive Textual Analysis, (MORAES; GALIAZZI, 2013). With the analysis it was possible to understand that the students pointed out different conceptions about the relevance of the curricular component of Chemistry. It is believed that such conceptions were constructed through school experiences, during the previous school years and emphasised in the 9th year of Elementary School, where the Science component covers topics related to Chemistry, or even, from the daily life of these students. The collected data can help the teachers from this subject to develop more effective practices that allow students to understand the real function and relevance of the study of Chemistry as a science.

Keywords: Basic education. Science teaching. Chemistry teaching. Conceptions of Students. Chemistry.

\section{INTRODUÇÃO}

Os estudantes quando iniciam seu processo de escolarização, já possuem algumas ideias elaboradas a respeito de muitos temas que envolvem as Ciências. Essas construções, em boa parte, foram desenvolvidas empiricamente, com base em suas experiências de tentativa e erro, ouvindo outras pessoas ou intermediadas pelos meios de comunicação. Esses conhecimentos prévios, segundo estudos, são a base para a elaboração de novas aprendizagens durante os anos de escolarização. De acordo com Miras (2011), é embasado nesses conhecimentos que os novos vão sendo construídos e incorporados à estrutura mental do indivíduo.

Sendo assim, ao ingressarem no Ensino Médio esses sujeitos já elaboraram algum conceito acerca da Química, por meio de experiências relativas ao componente curricular de Ciências do $9^{\circ}$ ano do Ensino Fundamental, ou mesmo por suas vivências fora do âmbito escolar. As Ciências, componente que permeia as grades curriculares do Ensino Fundamental, é abordada em todos os anos desse nível de ensino, seja de forma interdisciplinar - nos primeiros anos da Educação Básica, é comum o docente se ocupar com a alfabetização e letramento, porém, mencionando temas científicos durante o processo seja compondo um lugar entre os componentes curriculares. A Química tem seus conteúdos particulares entremeados aos demais temas trabalhados nas Ciências da Natureza, visto, por exemplo, na composição do corpo humano ou na fotossíntese realizada pelos vegetais. No $9^{\circ}$ ano, passa a ocupar um espaço com conteúdos dedicados às noções básicas, juntamente com a Física, servindo como introdução à dissociação das Ciências no Ensino Médio - Química, Física e Biologia - para um aprofundamento das temáticas já tratadas no Ensino Fundamental.

O modo transmissivo com que os conhecimentos relacionados à Química são muitas vezes trabalhados no Ensino Fundamental, privilegiando conceitos, fórmulas, nomenclaturas e classificações, por exemplo (LIMA; SILVA, 2012), podem encaminhar os estudantes para o entendimento que esse componente curricular não tem relação direta e próxima com o seu dia-a-dia e, dessa forma, pouco colabora para sua formação como cidadão, capaz interpretar o mundo com a possibilidade de interferir neste de forma consciente (CHASSOT, 1995). Desse modo, o entendimento dos estudantes sobre Química ao ingressarem no Ensino Médio, apresenta-se fragmentado, ou seja, para os estudantes, esse componente curricular é algo já pronto que precisa apenas ser assimilado. O real objetivo de aprender Química é, muitas vezes, compreendido como mais uma formalidade imposta, como os demais componentes curriculares que constituem o programa escolar.

As vivências dos estudantes também podem auxiliar na construção dos entendimentos do que representa a Química, visto que a própria palavra se encontra, de certo modo, naturalizada na mídia 
como algo que faz mal, ou é artificial, ou ainda de difícil entendimento. A Química se torna algo para poucos, produzida em laboratórios sofisticados e inalcançáveis ao entendimento destes sujeitos. Diante das premissas mencionadas, é comum que o indivíduo tenha uma visão distorcida desta ciência.

Desse modo, a presente investigação tem como objetivo compreender quais as concepções iniciais de estudantes do $1^{\circ}$ ano do Ensino Médio sobre a relevância do componente curricular de Química?

\section{A QUÍMICA E AS CIÊNCIAS NO ENSINO FUNDAMENTAL}

Ao longo do Ensino Fundamental, são tratados assuntos pertinentes à Química, Física e Biologia, constituindo o componente curricular de Ciências. No $9^{\circ}$ ano, esta área do conhecimento é normalmente constituída por conteúdos básicos pertencentes às áreas de Química e Física, apresentando noções, que reivindicam certo grau de abstração que muitas vezes, nesta fase escolar, o estudante não apresenta (LIMA; SILVA, 2012). Ao ingressarem no Ensino Médio, na medida em que os componentes curriculares sofrem uma maior fragmentação, rumando às especializações de Química, Física e Biologia, abarcadas na área de Ciências da Natureza, o estudante passa a ter a impressão de que tais conteúdos não foram explorados anteriormente e, comumente, sente-se perdido, pois não consegue estabelecer relações entre as informações, dados e conceitos que foram estudados até então nas Ciências durante seus anos anteriores de escolarização. Essa organização impede uma visão interdisciplinar das Ciências, com as diferentes áreas do conhecimento.

Raramente é explorado junto aos estudantes, por exemplo, a História da Ciência e como essa se expandiu ao longo do tempo, demonstrando a ele que se trata de um processo e não um produto pronto que necessita ser simplesmente assimilado. A carência no trato deste componente curricular como processo, nutre a ideia da Química como algo descontextualizado, complicado e que é de domínio exclusivo de cientistas, por exemplo. Rosa, Amaral e Mendes (2016) apontam que as abordagens nos livros didáticos de Química, no que diz respeito à História da Química, são realizadas de maneira frágil, carecendo de informações aos estudantes e referenciando de modo escasso o contexto histórico. Para as autoras, há uma valorização excessiva no produto final, sem que se considere as etapas de sua elaboração os “[...] acertos e erros pelos quais todo processo de evolução passa [...]" (ROSA; AMARAL; MENDES, 2016, p. 59), retratando a ausência de relação entre o fato em questão e os eventos históricos que permitiram a sua constituição e validação.

Cabe ressaltar que a expansão tecnológica de um país, necessita de investimentos em uma formação que propicie aos jovens, em todas as fases de escolarização, uma alfabetização científica adequada, assim como meios que estimulem a criatividade e a pesquisa. As Diretrizes Curriculares Nacionais para a Educação Básica - Brasil (2013) apontam que:

A escola constitui a principal e, muitas vezes, a única forma de acesso ao conhecimento sistematizado para a maioria da população. Esse dado aumenta a responsabilidade do Ensino Fundamental na função de assegurar a todos a aprendizagem dos conteúdos curriculares capazes de fornecer os instrumentos básicos para a inserção plena na vida social, econômica e cultural do país (BRASIL, 2013, p.113).

Para tanto, sabe-se que os métodos utilizados ainda são insuficientes. $O$ ato de ensinar não se trata apenas de conhecimento da matéria ou técnicas pedagógicas (CACHAPUZ et al., 2011). O docente deve ter em si ímpetos à pesquisa, a fim de descobrir os melhores caminhos para abordagem de cada conteúdo, exigindo flexibilidade e persistência. 
Como estratégias para o ensino de Ciências, Gil-Pérez (apud BORGES, 2007, p.87) sugere: "identificação das ideias prévias dos alunos, questionamento das mesmas, invenção ou introdução de conceitos, uso de novas ideias em situações abrangentes". Essas técnicas podem contribuir com o trabalho dos conteúdos científicos em todos os níveis de escolarização. Com isso, espera-se que o jovem consiga, de maneira crítica e consciente, participar de debates relacionados aos problemas contemporâneos como, por exemplo, o uso de medicações, agrotóxicos e alterações climáticas.

A articulação do conhecimento, com o cotidiano do estudante, usando seus entendimentos próprios para sistematizar novas aprendizagens, caracteriza-se como uma forma construtivista de ensinar Ciências. Ao professor, cabe possibilitar o processo, bem como, demonstrar que o estudo da Química, Física e Biologia são relevantes a todos e não apenas um conhecimento que precisa ser aprendido porque faz parte do currículo escolar pré-estabelecido. Também é de responsabilidade do docente conduzir os estudantes, de modo crítico, permitindo a compreensão de que os conhecimentos não devem estar desarticulados nos componentes curriculares, mas de maneira integrada.

\section{QUÍMICA E SUA RELEVÂNCIA COMO COMPONENTE CURRICULAR}

O componente curricular de Química apresenta como objetivo central, segundo Santos e Schnetzler (2014), habilitar o indivíduo para que esse possa ser capaz de tomar decisões diante das problemáticas que seu entorno apresenta e, assim, constituir-se cidadão autônomo e crítico. Em um sistema educacional que privilegia normalmente o acúmulo de informações, este objetivo se distancia do tratamento que a Química oferece, tanto no seu ensino quanto em sua aprendizagem no âmbito escolar, pois pouco se investe no diálogo e na discussão das realidades. É preciso possibilitar aos sujeitos envolvidos meios para expressar o que pensam, sabem, duvidam e questionam. Como saber as concepções dos estudantes, se eles não forem ouvidos? Se não forem provocados a manifestarem-se? De acordo com Moraes, Ramos e Galiazzi (2012, p.192),

Reconstruir significados implica conseguir atribuir novos sentidos às palavras já compreendidas a partir do discurso do cotidiano, o que precisa ser concretizado pelo envolvimento em outros tipos de discurso, entre eles o discurso científico, e mais especificamente o da Química.

Se o estudante no decorrer do Ensino Fundamental não identificou a relevância do aprender Ciências, esse processo reconstrutivo pode ocorrer no Ensino Médio, por meio da linguagem, fala ou escrita e, ao confrontar os diferentes entendimentos e saberes, reformular conceitos, mediados pelo professor. Perceber a relevância da Química enquanto ciência, numa perspectiva construtivista, necessita-se de atitude investigativa, versatilidade, mediação e olhar interdisciplinar às questões levantadas (MORAES, 2003).

As Ciências no Ensino Fundamental, obedece uma organização clássica, sendo comum não haver relação entre os conteúdos programáticos de um ano para outro. Desse modo, é habitual a separação em anos escolares o estudo do ambiente, seres vivos, corpo humano e conceitos básicos de Química e Física (LIMA; SILVA, 2012). Tais considerações normalmente são apresentadas descontextualizadas, numa perspectiva microscópica que impede a apropriação do sujeito que não compreende como significativa para os seus interesses (POZO; CRESPO, 2009).

Este modelo de organização curricular é reforçado pela maioria dos livros didáticos disponíveis que apresentam os conhecimentos de modo fragmentado e linear, sem considerar muitas vezes os conhecimentos que o estudante já apresenta ou a realidade onde se encaixa. Os conteúdos seguem um 
padrão para cada ano escolar, com conexões precárias entre si, estando ausentes temáticas cotidianas do universo dos estudantes, bem como conteúdos atitudinais que possam possibilitar, o saber ser e o saber conviver (MALDANER et al., 2012).

Quanto aos conhecimentos químicos, tem-se preocupação com a excessiva gama de informações justapostas, que privilegia "a nomenclatura das substâncias, como a representação de estruturas e equações químicas, em detrimentos de entendimento e significado" (LIMA; SILVA, 2012, p. 91). Para Lima e Aguiar Júnior (2000), os conteúdos pertinentes à Química são trabalhados de modo que se compreenda que as nomenclaturas e seus aspectos são capazes de proceder ou substituir o seu entendimento. Conforme Maldaner et al. (2012, p.112), "não se ensina/aprende o pensamento químico sobre o mundo; ensina-se 'coisas', que, de alguma forma, têm a ver com a Química".

Compreende-se que um componente curricular não representa um fim em si mesmo, mas um meio para que os estudantes possam entender o mundo que o cerca. Neste sentido, "estudamos/ensinamos Ciências para compreender coisas, processos, eventos do mundo natural e tecnológico em que estamos inseridos" (LIMA; SILVA, 2012, p.95). E, desse modo, desenvolver a qualidade formal, à medida em que os estudantes se apropriam dos saberes culturalmente desenvolvidos, sendo capazes de colocá-los a serviço da realidade (DEMO, 2007), assumindo-se como sujeitos históricos, capazes de dialogar com seu entorno e interferindo de modo positivo nas suas mudanças.

É necessária uma abordagem que permita ao indivíduo perceber a ciência não como algo pronto que necessita simplesmente ser assimilado, mas que se constitui algo dinâmico relacionado com o seu cotidiano. Valorizar a contextualização irá permitir a significação por parte do estudante, o envolvendo e o corresponsabilizando com o seu processo educativo (SANTOS; SCHNETZLER, 2014).

\section{PROCEDIMENTOS METODOLÓGICOS}

Esta investigação teve a participação de 69 estudantes do $1^{\circ}$ ano do Ensino Médio de uma escola pública estadual pertencente ao município de Novo Hamburgo, na região do Vale do Sinos, do estado do Rio Grande do Sul. Em 20165, o município de Novo Hamburgo registrou 2.436 matrículas no primeiro ano do Ensino Médio, cujos participantes dessa pesquisa correspondem a cerca de 1,68\% de jovens nesta faixa.

Por tratar-se de ingressantes no Ensino Médio, estes jovens são provenientes de diversas escolas de Ensino Fundamental, tanto da rede pública municipal e estadual, quanto particular, localizadas nas proximidades da escola onde foi realizado o estudo. Os participantes dessa pesquisa possuem idade aproximada de 16 anos e distribuídos em três turmas, no turno da manhã.

Nos primeiros dias de aula do ano letivo de 2016, realizaram-se algumas atividades com os estudantes, explorando suas realidades e fazendo uma avaliação dos conhecimentos prévios relacionados à Química, a fim de que se pudesse avançar na convergência entre conteúdo programático e interesse/necessidades dos grupos. Para a análise neste estudo foi considerado o seguinte questionamento: Qual a relevância que você percebe na Química? Solicitou-se aos estudantes que escrevessem suas ideias e que não se preocupassem com a rigorosidade nas respostas, apenas que registrassem suas impressões e aquilo que realmente a pergunta representava a eles. Teve-se o cuidado de ler a pergunta conjuntamente com os grupos, esclarecendo, caso houvesse alguma dúvida com relação à questão. Ao final da atividade, as respostas foram recolhidas sem a identificação dos estudantes, mantendo o anonimato na pesquisa.

\footnotetext{
${ }^{5}$ Disponível em: <http://www.qedu.org.br>. Acesso em: 20 jul. 2017.
} 
As respostas formuladas pelos 69 jovens, com idade média de 16 anos, compuseram o corpus de análise desse estudo e foram submetidas à Análise Textual Discursiva (ATD), descrita por Moraes e Galiazzi (2013). Esta metodologia qualitativa de análise tem por intenção a compreensão das ideias expressas no corpus e se compõe pelos seguintes passos: (a) desconstrução dos textos (unitarização): as ideias apresentadas pelos participantes de pesquisa são fragmentadas, constituindo unidades de sentido; (b) categorização: estabelecimento de relações entre essas unidades, agrupando-as conforme semelhanças e de acordo com o contexto do qual foram retiradas. Esta etapa pode consistir em categorias iniciais, intermediárias, finais, bem como podem ser construídas a priori ou a posteriori à análise (categorias emergentes). É uma decisão do pesquisador frente aos dados apresentados conjuntamente ao aporte teórico que o embasa; (c) metatextos: as ideias emergidas por meio da etapa de categorização são transpostas para um texto, com um apanhado das ideias obtidas por meio da análise do corpus.

Os participantes foram identificados na análise como ' $a$ ' e um número destinado a cada correspondente - por exemplo, participante de pesquisa 'a.17' -, de forma aleatória, sem distinção de turmas. Optou-se pela utilização de categorias emergentes, procurando dar voz às ideias manifestadas dos sujeitos participantes.

\section{RESULTADOS E ANÁLISE}

Por meio da análise, emergiram duas categorias finais: a Química: ciência distante da realidade e a Química, a vida e o cotidiano, que expressam as concepções dos estudantes ingressantes no Ensino Médio sobre a relevância da Química.

\subsection{A QUÍMICA: CIÊNCIA DISTANTE DA REALIDADE}

Esta categoria procurou abarcar as ideias dos estudantes sobre a importância da Química. É possível perceber em depoimentos como do estudante a.59 "A Química é muito importante para tudo que há Ciências". Essa afirmação demonstra que não há clareza por parte do estudante sobre a Química como ciência. A noção de importância pode ter sido transmitida ao estudante por meio das exposições realizadas por professores em anos anteriores ou mesmo de outras experiências vivenciadas por ele. Não transparece ter conhecimento do real motivo, da importância, sabe apenas que há correlação com as Ciências.

Alguns participantes da pesquisa não demonstraram conhecimento sobre a Química ser um componente das Ciências ou mesmo estabeleceram correspondência manifestando de alguma forma essa associação. Nota-se que os estudantes aqui mencionados apresentam dificuldades em estabelecer uma ligação entre a Química e a Ciências por meio dos conteúdos estudados anteriormente, conforme podese perceber no trecho apresentado referente ao participante a.21.: "Penso na Química como aquela matéria que tem líquidos coloridos que explodem e Ciências os estudos de animais, natureza". Esta mesma noção é percebida no depoimento do participante a.47: "Eu acho que a Química fala mais de misturas de elementos e a Ciências fala da evolução das coisas". Gabel (1993) destaca a importância de um trabalho focado nas dimensões macroscópica, microscópica e simbólica da Química para a descrição de fenômenos comuns como possibilidade de potencializar o ensino, com vistas à realidade dos estudantes. Tais considerações são relevantes, pois uma visão do todo faz com os problemas da vida real ultrapassem os muros da escola. 
A imagem laboratorial atribuída a Química, como sendo uma ciência construída e verificada apenas por instrumentos e reações é uma ideia contida em muitos estudantes e, de acordo com Galiazzi e Gonçalves (2004, p.328), a atividade experimental deve superar visões simplistas:

Pela observação se chega às teorias aceitas pela comunidade científica; pela experimentação em sala de aula se valida e comprova uma teoria; as atividades experimentais são intrinsecamente motivadoras e que atividades experimentais contribuem para captar jovens cientistas.

Pode-se inferir que, ao longo do processo de escolarização dos participantes dessa pesquisa, houve escassas tentativas de aproximação entre o cotidiano e conteúdos que fizessem correlações à Química. Estas construções devem ocorrer gradualmente, não somente no último ano do Ensino Fundamental, quando há um contato mais próximo com essa parte da ciência. Tais situações podem advir pela limitação do professor que, ao explicar determinado conteúdo, não correlaciona naturalmente com assuntos ligados à Química, como por exemplo, durante a abordagem do funcionamento do Sistema Digestório, dinâmica de um vulcão ou as propriedades da água.

A organização tradicional dos conteúdos de Química no Ensino Fundamental, normalmente tem início com conceitos abstratos, como os modelos atômicos, por exemplo, valorizando o aspecto microscópico desta ciência. Este tema é de difícil compreensão para os estudantes neste período de escolarização, requerendo estudos introdutórios que valorizem conhecimentos relacionados à transformação da matéria. Estas formas desconexas de como os assuntos referentes à Química são apresentados no Ensino Fundamental, remete a concepções falsas (LIMA; SILVA, 2012) que podem persistir ao longo do processo escolar, se constituindo como obstáculos para aprendizados futuros.

Considerando o modo de abordagem, é comum que tradicionalmente se priorize a a competência memorística dos estudantes na reprodução de classificações dos temas abordados. Esta configuração de trabalho tem produzido um ensino que nega ao estudante a oportunidade de compreender e "estabelecer relações entre as teorias criadas para explicar a constituição da matéria e o comportamento físico químico dos materiais" (LIMA; SILVA, 2012, p. 91).

A fragmentação naturalizada do conhecimento que ocorre durante a escolarização não limita somente os estudantes em seus aprendizados, mas também estreita a visão do professor quanto às dimensões que um determinado conteúdo pode ser explanado, impedindo que o estudante possa realizar variadas conexões e, com isso, a complexificação do conhecimento adquirido. Esta constatação é confirmada por Rocha Filho; Basso e Borges (2009, p. 21): “[...] a medida que os estudos prosseguem [passagem do Ensino Fundamental para o Ensino Médio] e as Ciências são estudadas em diversas disciplinas, cada uma delas tende a perder de vista os processos de pensamento dos alunos, provocando certa alienação". A falta de relação progressiva que ocorre à medida em que o estudante avança em seus estudos, afasta-o de certas áreas por falta da percepção de conexões com o cotidiano e pela dificuldade que alguns professores atribuem às suas disciplinas, orgulhando-se de serem mais difíceis. Torna o ensino tedioso e sem vistas à vida real do indivíduo.

Percebe-se ainda dentro desta categoria a visão de alguns estudantes associando a aprendizagem da Química unicamente à cálculos e formulações. Demonstram ter conhecimentos de alguns conceitos usualmente abordados, como átomos, reações, ligações químicas, mas não manifestam aproximações com seu cotidiano, como constatado no depoimento do participante a.3: "Que ensina reação química, tabela, elementos químicos, como formar bases e ácidos e transformar elementos". Esta mesma percepção tem o estudante a.41: "Vejo como uma disciplina que faz vários projetos envolvendo elementos químicos”. Mortimer (2000, p. 274) faz referência aos currículos conteudistas: 
A quantidade de conceitos - ou definições? - E procedimentos que são introduzidos a cada aula, a cada página da maioria dos livros didáticos, é muito grande para que seja possível ao aluno, em tão pouco tempo, compreendê-los e ligá-los logicamente numa estrutura mais ampla que dê significado à aprendizagem da química. Aos alunos fica a impressão de se tratar de uma ciência totalmente desvinculada da realidade, que requer mais memória do que o estabelecimento de relações.

É perceptível que aos estudantes permanecem apenas nomenclaturas, termos soltos, sem qualquer relação com a realidade, perfazendo apenas um item de uma lista extensa de conteúdos. A pouca simpatia despertada em alguns pelo componente curricular de Química também pode ser associada à ligação que os estudantes fazem com os cálculos. As dificuldades observadas no componente curricular de Matemática, em alguns casos, parecem ser transferidas também às demais matérias envolvendo este tipo de raciocínio. Esta situação é demonstrada pela declaração do participante a.35: "tenho dificuldades em cálculos, mas acho importante aprender". A sensibilidade do professor em tratar essas questões que, muitas vezes, vem acompanhando toda a vida escolar do estudante é importante não apenas para expor as outras faces da Química, mas para ajudar o docente na construção da figura do seu estudante e compreender que as dificuldades não se encontram isoladas disciplinarmente. Um diálogo conjunto, um planejamento integrado entre as áreas do conhecimento são caminhos possíveis na desmistificação destes ranços, e que conduzem o estudante à desistência de aprender determinado conteúdo. Contudo, também é importante que o professor reflita sobre de que forma e o que vem exigindo como algo essencial ao aprendizado da Química, pois conforme Mortimer (2000), a repetição acrítica de formulações didáticas pode converter a Química escolar em uma ciência ainda mais longínqua de suas aplicações na sociedade.

Como aspecto relacionado a essa categoria, explora-se depoimentos que revelam não ter visto qualquer conteúdo relacionado ao componente curricular Química, ou como a declaração do participante a.6: "minha primeira vez nessa disciplina", limitando os conhecimentos químicos as barreiras impostas por esse componente curricular. Conforme análises já expostas anteriormente, é notável a falta de relação com as demais áreas do conhecimento ou mesmo no tratamento dos assuntos cotidianos. Esta carência demonstra o trabalho de excelência exercido pela disciplinarização, expondo ao educando que ele somente é conhecedor de assuntos da disciplina que já cursou. É necessária a realização de um exercício reflexivo, rotineiro, mostrando aos estudantes que seus conhecimentos devem ultrapassar qualquer limite imposto por matérias. Observando o depoimento do sujeito a.63: "Acho interessante, mas não vejo utilidade no dia a dia", exibe que o que vem sendo tratado nos anos escolares não o atinge o seu cotidiano, servindo apenas para responder as extensas listas de exercícios que compõem os livros didáticos escolares.

\subsection{A QUÍMICA, A VIDA E O COTIDIANO}

Como segunda categoria de análise, observaram-se nos depoimentos dos participantes que um grupo - sete estudantes - foi capaz de estabelecer relações entre o componente curricular Química e o seu dia-a-dia. Conforme a declaração do participante a.17: "Hoje em dia, quando a gente sai na rua, quando almoça, em tudo que fazemos, a Química está presente. Por isso acho muito importante". Não há como precisar quando ou onde este estudante adquiriu tal conhecimento, mesmo porque os participantes realizaram seu Ensino Fundamental em escolas variadas e, ainda assim, deve-se considerar que cada indivíduo aprende não apenas no ambiente escolar, mas por outros meios como a mídia, amigos e convívio familiar. Também se percebe no relato do participante a.40: "Importante para a humanidade 
pois promove a cura de doenças e aumenta a expectativa de vida". Cardoso e Colinvaux (2000, p. 401), afirmam que:

\begin{abstract}
Devido ao fato de viver em sociedade, adquirimos um conhecimento que se torna progressivamente mais estruturado e claro por estarmos continuamente discutindo, elaborando e reelaborando nossas ideias com outros. Por outro lado, o contexto escolar muitas vezes não possibilita uma maior discussão entre os alunos acerca dos conhecimentos adquiridos, seja por limitação de tempo ou ainda devido à inadequação de nossos currículos e práticas pedagógicas.
\end{abstract}

Alguns estudos têm se preocupado em compreender a concepção dos estudantes sobre o componente curricular de Química. Na investigação realizada por Faleiro et al. (2012), em que participaram 118 estudantes do Ensino Médio de diferentes anos, concluiu que apenas 29,6\% apresentam concepções que se aproximam do conhecimento científico. Neste estudo os estudantes compreendem que a necessidade de atividades práticas que possibilitem identificar a importância da Química no cotidiano.

Em outro estudo realizado por Gonçalves, Camara e Dal-Farra (2015), acerca da compreensão de concepções dos estudantes relacionadas à Química, os dados obtidos permitiram demonstrar que os mesmos apresentam uma visão positiva à respeito da Química e avaliam que esta ciência contribui para a vida das pessoas. Os autores apontam para a necessidade de uma reflexão por parte dos docentes da referida componente, no sentido de implementar ações que possibilitem a contextualização e a articulação da Química com a sociedade e o ambiente.

Promover situações que levem os estudantes a discutirem entre pares as ideias do que está sendo exposto na disciplina, ou na mídia, relacionando com seu dia-a-dia, instigando-os à reflexão, ao questionamento, é fundamental para que estas conexões que se esperam entre o que é trabalhado no ambiente da escola e a vida sejam efetivas. $O$ docente não deve pensar que o tempo destinado a esse tipo de atividade é perdido ou inútil, preocupado somente com o conteúdo a ser trabalhado. E também não pode esperar resultados milagrosos de atividades reflexivas pontuais. A aproximação da pesquisa com a sala de aula se mostra uma alternativa interessante a esse tipo de debate, levando o estudante a perceber que para a resolução de problemas não há barreiras disciplinares e que todos os saberes são importantes na busca pela solução da questão.

\title{
6 CONSIDERAÇÕES FINAIS
}

O estudo teve como intuito responder a seguinte questão: Quais as concepções de estudantes do $1^{\circ}$ ano do Ensino Médio sobre a relevância do componente curricular de Química? As ideias apontadas pelos estudantes revelaram que alguns compreendem que a Química representa algo distante da sua realidade e outros, como um componente presente na sua vida diária. Porém, poucos estudantes do estudo em questão demonstraram algum tipo de conexão entre a Química e o cotidiano. Tal constatação demonstra que é necessário ao professor não se detenha apenas aos conteúdos, cumprindo os planos de estudo previstos para suas aulas, mas demonstre a esses estudantes que a escola está a serviço da vida e não o contrário. Não se trata de uma tarefa simples nem ao estudante, muito menos ao docente. Mas, quando o professor se sujeita a esse papel, de não ser apenas um transmissor de conteúdos, mas tão aprendente quanto o estudante, proporciona um espaço para aprendizagem muito mais prazeroso, trazendo ao protagonismo o estudante, em suas aprendizagens. Os dados coletados e analisados podem colaborar com os professores deste componente curricular, no sentido de desenvolver práticas mais 
efetivas que proporcionem aos estudantes compreender a real função e relevância do estudo da Química, enquanto ciência.

\section{REFERÊNCIAS}

BORGES, R. M. R. Educação Científica Escolar. In: BORGES, R. M. R. Em debate: Cientificidade e educação em Ciências. 2. ed. Porto Alegre: EDIPUCRS, 2007. p.85-109.

BRASIL. Diretrizes Curriculares Nacionais da Educação Básica. Ministério da Educação.

Secretária de Educação Básica. Diretoria de Currículos e Educação Integral - Brasília: MEC, SEB, DICEI, 2013.

CACHAPUZ, A. et al. Necessária Renovação do Ensino de Ciências. 3. ed. São Paulo: Cortez, 2011.

CARDOSO, S. P.; COLINVAUX, D. Explorando a Motivação para Estudar Química. Química Nova, v.23, n.2, p.401-404, 2000.

CHASSOT, A. A ciência através dos tempos. São Paulo: Moderna, 1995.

DEMO, P. Educar pela pesquisa. 8. ed. Campinas: Autores Associados, 2007.

FALEIRO, J. H. et al. Concepções sobre química e ensino de química de discentes de uma escola pública de Orizona (Goiás). In. Enciclopédia Biosfera, Centro Científico Conhecer, Goiânia, v. 8, n. 15; p. 2012.

GABEL, Dorothy L. Use of the particle nature of matter in developing conceptual understanding. Journal of Turkish Science Education, v. 70, n. 3, p. 193-4, mar. 1993. Disponível em: <http://pubs.acs.org/doi/pdf/10.1021/ed070p193>. Acesso em: 02 jul. 2017.

GALIAZZI, M. C.; GONÇALVES, F.P. A Natureza Pedagógica da Experimentação: Uma pesquisa na licenciatura em química. Química Nova, v..27, n.2, p. 326-331, 2004.

GONÇALVES, F. C. L.; CAMARA, V. F. S.; DAL-FARRA, R. A. Concepções de alunos ingressantes no ensino médio sobre química: contribuições para a prática docente. In: Anais do X Encontro Nacional de Pesquisa em Educação em Ciências - X ENPEC. Águas de Lindóia, SP - 24 a 27 de novembro de 2015.

LIMA, M. E. C. C; AGUIAR JÚNIOR, O. Ciências Física e Química no ensino fundamental. Presença Pedagógica. Belo Horizonte, v. 6, n. 31, p. 39-49, 2000.

LIMA, M. E. C. C; SILVA, N. S. A Química no Ensino Fundamental: uma proposta em ação. In: ZANON, L.B.; MALDANER, O. (org.). Fundamentos e propostas de ensino de química para a educação básica no Brasil. Ijuí: UNIJUÍ, p. 89-107, 2012.

MALDANER, O. et al. Currículo Contextualizado na área de ciência da natureza e suas tecnologias: a situação de estudo. In: ZANON, L.B.; MALDANER, O.A (org.). Fundamentos e propostas de ensino de química para a educação básica no Brasil. Ijuí: UNIJUÍ, p. 109-138, 2012.

MIRAS, M. Um ponto de partida para a aprendizagem de novos conteúdos: os conhecimentos prévios. In: COLL, C. et al. (org.) O construtivismo na sala de aula. 6. ed. São Paulo: Ática, 2011, p. 57-77.

MORAES, R; RAMOS, M. G; GALIAZZI, M. do C. Aprender Química: Promovendo excursões em discursos da química. In: ZANON, L.B; MALDANER, O. (org.). Fundamentos e propostas de ensino de química para a educação básica no Brasil. Ijuí: UNIJUí, p. 191-209, 2012. 
MORAES, R.; GALIAZZI, M. C. Análise Textual Discursiva. 2. ed. Ijuí: UNIJUÍ, 2013.

MORAES, R. É Possível ser Construtivista no Ensino de Ciências? In: MORAES, R (Org.)

Construtivismo e Ensino de Ciências: Reflexões epistemológicas e metodológicas. 2. ed. Porto Alegre: EDIPUCRS, 2003, p.103-129.

MORTIMER, E. F. A proposta curricular de Química do Estado de Minas Gerais: Fundamentos e Pressupostos. Química Nova, v.23, n.2, p. 273-283, 2000.

POZO, J. I.; CRESPO, M. A. G. A aprendizagem e o ensino de Ciências: do conhecimento cotidiano ao conhecimento científico. $5^{\mathrm{a}}$ ed. Porto Alegre: Artmed, 2009.

ROCHA FILHO, J. B.; BASSO, N. R.; BORGES, R. M. R. Transdisciplinaridade: a Natureza íntima da Educação Científica. 2. ed. Porto Alegre, EDIPUCRS, 2009.

ROSA, D. L.; AMARAL, A. M.; MENDES, A. N. F. História da Química na Educação Básica: uma investigação nos livros didáticos. Revista Conhecimento Online. Novo Hamburgo, a.8, v.1, p. 57-67, 2016. Disponível em:

<http://periodicos.feevale.br/seer/index.php/revistaconhecimentoonline/article/view/350/404〉. Acesso em: 13 abr. 2017.

SANTOS, W. L. P.; SCHNETZLER, R. P. Educação Química. 4. ed. Ijuí: UNIJUÍ. 2014. 